\title{
APOE and FABP2 Polymorphisms and History of Myocardial Infarction, Stroke, Diabetes, and Gallbladder Disease
}

\author{
Ikuko Kato, ${ }^{1,2}$ Susan Land, ${ }^{1,3}$ Jill Barnholtz-Sloan, ${ }^{4}$ and Richard K. Severson ${ }^{5}$ \\ ${ }^{1}$ Karmanos Cancer Institute, School of Medicine, Wayne State University, 4100 John R. Street, Detroit, MI 48201, USA \\ ${ }^{2}$ Department of Pathology, School of Medicine, Wayne State University, Detroit, MI 48201, USA \\ ${ }^{3}$ Department of Obstetrics and Gynecology, School of Medicine, Wayne State University, Detroit, MI 48201, USA \\ ${ }^{4}$ Case Comprehensive Cancer Center, Case Western Reserve University School of Medicine, Cleveland, OH 44106, USA \\ ${ }^{5}$ Department of Family Medicine and Public Health Sciences, School of Medicine, Wayne State University, Detroit, MI 48201, USA
}

Correspondence should be addressed to Ikuko Kato, katoi@karmanos.org

Received 24 February 2011; Revised 11 May 2011; Accepted 20 June 2011

Academic Editor: Bruce Griffin

Copyright ( 2011 Ikuko Kato et al. This is an open access article distributed under the Creative Commons Attribution License, which permits unrestricted use, distribution, and reproduction in any medium, provided the original work is properly cited.

\begin{abstract}
Dysfunctional lipid metabolism plays a central role in pathogenesis of major chronic diseases, and genetic factors are important determinants of individual lipid profiles. We analyzed the associations of two well-established functional polymorphisms (FABP2 A54T and APOE isoforms) with past and family histories of 1492 population samples. FABP2-T54 allele was associated with an increased risk of past history of myocardial infarction (odds ratio $(\mathrm{OR})=1.51$ ). Likewise, the subjects with APOE4, compared with $E 2$ and $E 3$, had a significantly increased risk of past history myocardial infarction $(\mathrm{OR}=1.89)$. The OR associated with APOE4 was specifically increased in women for past history of myocardial infarction but decreased for gallstone disease. Interactions between gender and $A P O E$ isoforms were also significant or marginally significant for these two conditions. FABP2-T54 allele may be a potential genetic marker for myocardial infarction, and APOE4 may exert sex-dependent effects on myocardial infarction and gallbladder disease.
\end{abstract}

\section{Introduction}

Dysfunctional lipid metabolism plays a central role in pathogenesis of major chronic diseases, including cardiovascular diseases, insulin-independent diabetes, and gallbladder disease $[1,2]$. While environmental factors, such as diet, are important determinants of circulating lipid concentrations, heritabilities of lipid profiles have been well elucidated in twin studies [3-6]. Because of the wellestablished association between circulating cholesterol levels and cardiovascular diseases, genes involved in cholesterol synthesis and transport have been more extensively studied than the others involved in long-chain fatty acids (LCFAs) and phospholipids [2, 7-11].

Among a number of genetic loci that have been examined thus far, APOE isoforms are the first common genetic polymorphisms that were linked to cardiovascular diseases (CVDs) and Alzheimer's disease [9, 12-14]. ApoE is a multifunctional protein that is synthesized by the liver and several peripheral tissues and cell types, including macrophages, and a major component of several classes of plasma lipoproteins including triglyceride-rich very-low-density lipoprotein (VLDL) [13]. The protein is involved in the efficient hepatic uptake of lipoprotein particles, stimulation of cholesterol efflux from macrophage foam cells in the atherosclerotic lesion, and the regulation of immune and inflammatory responses and thus has key roles in lipid transport in the plasma and in the central nervous system as well as in responses to the dietary fat content and fatty acid compositions [13-15]. Three isoforms, E2, E3, and E4, are defined by combinations of amino acid (cysteine/arginine) substitutions at codons 112 and 158 [12-14]. The most recent meta-analysis by Bennet et al. demonstrated approximately linear relationships of $A P O E$ genotype (E2 through E4) with both LDL cholesterol levels and coronary risk, highlighting the effect of E2 [16], while two earlier analyses emphasized the adverse effect of E4 on coronary risk $[17,18]$. Some studies also suggest that genetic effects of $A P O E$ on several lipid parameters may be modified by gender [19-25]. FABP2 encodes intestinal fatty acid binding protein, 
and its alanine $(\mathrm{A}) /$ threonine $(\mathrm{T})$ substitution at codon 54 in exon-2 [26] has received research interest as T54-containing FABP2 protein has greater ability to transport LCFA than A54-containing protein [27]. T54 allele has been associated with higher plasma triglycerides [28-30] and free fatty acids levels [31], a higher postprandial lipemic response [32, 33], and higher postprandial glucose and insulin levels $[26,34$, $35]$, as well as with CVD and type 2 diabetes in some studies [36-41]. Due to their extensively studied roles in responses to dietary fat intake as well as to the established functional effect in vitro $[8,9,14,15,27-35]$, these two polymorphisms were originally chosen for the parent study to elucidate the association with colorectal cancer [42], although the list of genes is now growing, including APOA5 and $L P L[2,9-11]$, owing to advance in genotyping technologies.

These polymorphisms are likely to have implications in multiple chronic conditions related to lipid metabolism, but most of the published studies to date have focused on single conditions. Using the data from a population-based casecontrol study [42], we had an opportunity to address if these functional polymorphisms are associated with histories of myocardial infarction, stroke, diabetes, and gallbladder disease.

\section{Methods}

2.1. Study Design. This study was secondary data analysis of the control subjects who participated in a population-based case-control study for colorectal cancer in Metropolitan Detroit, Mich, USA. Details concerning the ascertainment, recruitment, and characteristics of the study subjects of the parent study have been described elsewhere [42]. The study was approved by Wayne State University Human Investigation Committee and all subjects gave written informed consent to participate in the study. In brief, eligible subjects were between 45 and 80 years of age at time of ascertainment, with a working telephone and no prior history of any invasive cancer, in situ colorectal cancer, or colectomy and were recruited through random digit dialing. These subjects consisted of $57 \%$ of females, $43 \%$ of males, $26.5 \%$ of African Americans, $69.2 \%$ of NonHispanic Caucasians, and $4.3 \%$ of other racial groups. The subjects were interviewed over the telephone using structured questionnaires regarding their usual diet and other risk factors for colorectal cancer (e.g., demographics, smoking, physical activity, medication/supplement use, and own and family history of major chronic diseases) for the time-period preceding cancer diagnosis for the cases (approximately 2 years prior to the interview). Specifically, a semiquantitative food frequency questionnaire (FFQ), Block 98.2 (Block Dietary Data Systems, Berkeley, Calif), that was validated against multiple diet records $[43,44]$ was used to estimate daily nutrient intake. This questionnaire was chosen based on its superiority to categorize individuals on energy from fat as compared to the Willett instrument [45] as dietary fat was a main focus of the study. The residual method described by Willett and Stampfer was used to calculate energy-adjusted nutrient intake [46]. The study participants provided either peripheral blood $(71 \%)$ or buccal cell samples (29\%) for TaqMan genotyping for $A p o E$ and $F A B P 2$ polymorphisms. Both polymorphisms were found to be in Hardy-Weinberg equilibrium using $P=0.05$ as the threshold.

2.2. Statistical Analysis. Out of the 1547 controls originally consented to the study, 1492 with all study parameters were included in this analysis. The following histories of diseases were queried for subjects themselves as well as for their first degree of family members (parents, children, and siblings): myocardial infarction/heart attack, stroke and transitional ischemic attack, diabetes, and gallstone/gallbladder surgery. Odds ratios (ORs) and 95\% confidence intervals (CIs) for history (own, family, or both) of these diseases associated with FABP2 and $A P O E$ polymorphisms were estimated using an unconditional logistic regression model [47], adjusting for selected covariates, which included demographic variables (age, sex, race (African American versus others), and educational level), family size (numbers of own siblings and children), common risk factors for major chronic diseases (pack-years of cigarette smoking, body mass index (body weight $(\mathrm{kg})$ /body height $\left.(\mathrm{m})^{2}\right)$, and alcohol intake), and dietary covariates (energy-adjusted saturated fat, cholesterol, dietary fiber, and total calcium intakes) that were known risk factors for the diseases of interest and differed by either $F A B P 2$ or $A P O E$ genotype. For the FABP2 polymorphism, the $A A$ genotype was used as the reference to calculate the ORs for AT, TT, or those combined. E3 homozygotes were used as the reference for $A P O E$ to calculate ORs associated with E2 (E2/E2, E2/E3, and E2/E4) and E4 (E4/E4 and E4/E3) isoforms, while the ORs were also calculated for $E 4$ compared with E2 and E3 combined. The decision to include E2/E4 to E2 was based on the meta-analysis by Bennet et al. that clearly demonstrated that total and LDL cholesterol levels were lower in the E2/E4 genotype than in the wild-type E3/E3 group [16]. Tests for linear trend in the logit of risk associated with these ordinal categorical genotypes were performed using equally spaced scores to the categories. In addition, the ORs were calculated stratified by gender, and the interactions between the polymorphisms and gender were tested by including their multiplicative interaction terms. All statistical analyses were performed using SAS version 9.

\section{Results}

Overall, a total of 452 subjects reported previous diagnosis or treatment for one of the diseases specified above, while 1095 reported family history of these diseases. Out of these 452, 357 had additional family history. Subjects who had been diagnosed with these diseases were older than those who had not. While diabetes and gallbladder disease were common as past histories, heart attack was most prevalent as a family history (Table 1).

As shown in Table 2, the subjects who carried at least one FABP2-T54 allele were at an increased risk of past history of myocardial infarction $(\mathrm{OR}=1.51,95 \% \mathrm{CI}$ : 1.01-2.27). There was no difference between homozygotes and heterozygotes. The risk of myocardial infarction was further increased if they had family history (OR $=1.93,95 \%$ CI: 1.15-3.23). 
TABLE 1: The numbers of study subjects who reported past or family history of selected chronic diseases and their mean ages at study enrolment.

\begin{tabular}{|c|c|c|c|c|c|c|}
\hline \multirow{3}{*}{ Diseases } & \multicolumn{6}{|c|}{ Medical history } \\
\hline & \multicolumn{2}{|c|}{ Own } & \multicolumn{2}{|c|}{ Family } & \multicolumn{2}{|c|}{ Both } \\
\hline & No. & Mean age & No. & Mean age & No. & Mean age \\
\hline Myocardial infarction & 110 & 66.7 & 663 & 62.8 & 66 & 66.3 \\
\hline Stroke & 74 & 68.2 & 444 & 62.6 & 21 & 66.0 \\
\hline Diabetes & 204 & 64.7 & 573 & 62.1 & 123 & 64.6 \\
\hline Gallbladder disease & 203 & 64.7 & 280 & 60.8 & 53 & 63.7 \\
\hline Any of the above & 452 & 65.0 & 1095 & 62.4 & 357 & 65.0 \\
\hline None of the above & 1040 & 61.3 & 397 & 62.5 & 1135 & 61.6 \\
\hline
\end{tabular}

TABLE 2: Odds ratios (ORs) and 95\% confidence intervals (CIs) for history of selected chronic diseases according to FABP2 genotypes.

\begin{tabular}{|c|c|c|c|c|c|c|c|c|c|c|}
\hline \multirow{3}{*}{ Diseases } & \multirow{3}{*}{ Genotype } & \multicolumn{9}{|c|}{ Medical history } \\
\hline & & \multicolumn{3}{|c|}{ Own } & \multicolumn{3}{|c|}{ Family } & \multicolumn{3}{|c|}{ Both } \\
\hline & & Yes/No & OR & $95 \%$ CI & Yes/No & OR & $95 \% \mathrm{CI}$ & Yes/No & OR & $95 \% \mathrm{CI}$ \\
\hline \multirow{5}{*}{ Myocardial infarction } & AA & $51 / 777$ & 1.00 & - & $358 / 470$ & 1.00 & - & $27 / 801$ & 1.00 & - \\
\hline & AT & $51 / 509$ & 1.55 & $1.02-2.35$ & $262 / 298$ & 1.14 & $0.92-1.42$ & $35 / 525$ & 2.04 & $1.20-3.46$ \\
\hline & TT & $8 / 96$ & 1.33 & $0.60-2.98$ & $43 / 61$ & 0.94 & $0.62-1.43$ & $4 / 100$ & 1.30 & $0.44-3.87$ \\
\hline & $\mathrm{AT}+\mathrm{TT}$ & $59 / 605$ & 1.51 & $1.01-2.27$ & $305 / 359$ & 1.11 & $0.90-1.36$ & $39 / 625$ & 1.93 & $1.15-3.23$ \\
\hline & & $P=0.089$ & & & $P=0.595$ & & & $P=0.051$ & & \\
\hline \multirow{5}{*}{ Stroke } & AA & $41 / 787$ & 1.00 & - & $258 / 570$ & 1.00 & - & $13 / 815$ & 1.00 & - \\
\hline & AT & $30 / 530$ & 1.11 & $0.67-1.84$ & $158 / 402$ & 0.86 & $0.68-1.09$ & $8 / 552$ & - & - \\
\hline & TT & $3 / 101$ & 0.65 & $0.19-2.20$ & $28 / 76$ & 0.85 & $0.54-1.36$ & $0 / 104$ & - & - \\
\hline & $\mathrm{AT}+\mathrm{TT}$ & $33 / 631$ & 1.05 & $0.64-1.70$ & $186 / 478$ & 0.86 & $0.68-1.08$ & $8 / 656$ & 0.80 & $0.32-1.97$ \\
\hline & & $P=0.869$ & & & $P=0.220$ & & & $P=0.406$ & & \\
\hline \multirow{5}{*}{ Diabetes } & AA & $118 / 710$ & 1.00 & - & $298 / 530$ & 1.00 & - & $75 / 753$ & 1.00 & - \\
\hline & AT & $76 / 484$ & 0.94 & $0.68-1.31$ & $234 / 326$ & 1.32 & $1.06-1.65$ & $44 / 516$ & 0.88 & $0.59-1.32$ \\
\hline & TT & $10 / 94$ & 0.66 & $0.32-1.35$ & $41 / 63$ & 1.26 & $0.82-1.93$ & $4 / 100$ & 0.46 & $0.16-1.30$ \\
\hline & $\mathrm{AT}+\mathrm{TT}$ & $86 / 578$ & 0.90 & $0.66-1.24$ & $275 / 389$ & 1.31 & $1.06-1.63$ & $48 / 616$ & 0.82 & $0.55-1.21$ \\
\hline & & $P=0.335$ & & & $P=0.029$ & & & $P=0.168$ & & \\
\hline \multirow{5}{*}{ Gallbladder disease } & AA & $112 / 716$ & 1.00 & - & $148 / 680$ & 1.00 & - & $30 / 798$ & 1.00 & - \\
\hline & AT & $81 / 479$ & 1.05 & $0.76-1.44$ & $118 / 442$ & 1.20 & $0.91-1.59$ & $21 / 539$ & 0.93 & $0.52-1.68$ \\
\hline & $\mathrm{TT}$ & $10 / 94$ & 0.74 & $0.37-1.49$ & $14 / 90$ & 0.73 & $0.40-1.33$ & $2 / 102$ & 0.56 & $0.13-2.43$ \\
\hline & $\mathrm{AT}+\mathrm{TT}$ & $91 / 573$ & 1.00 & $0.73-1.36$ & $132 / 532$ & 1.13 & $0.86-1.47$ & $23 / 641$ & 0.88 & $0.50-1.56$ \\
\hline & & $P=0.710$ & & & $P=0.876$ & & & $P=0.512$ & & \\
\hline
\end{tabular}

ORs were adjusted for age, sex, race, educational levels, cigarette smoking (pack-years), alcohol intake, body mass index, energy-adjusted dietary saturated fat, cholesterol, fiber and total calcium intakes, and family size. $P$ values for a linear trend for the number of T-alleles.

For other diseases, there were no consistent associations with the T54 allele, except an increased risk of family history of diabetes $(P$ value for trend $=0.029)$. Likewise, the subjects with the APOE4 genotypes had a significantly increased risk of past history of myocardial infarction compared with E2 and E3 combined (OR $=1.89$; 95\% CI: $1.24-$ 2.88) (Table 3). The similar trend was observed for the subjects with both past and family histories of myocardial infarction, but it remained marginally statistically significant $(\mathrm{OR}=1.64,95 \% \mathrm{CI}: 0.97-2.80)$. There were no statistically significant associations between $A P O E$ genotypes and the rest of the diseases. Although the information was available only for the subjects themselves, the prevalence of high blood cholesterol or use of cholesterol-reducing medication increased progressively from $E 2$ through $E 4$ with a significant linear trend $(P=0.002)$ (data not shown).

Table 4 presents gender-specific ORs for past history of these conditions according to the APOE polymorphism. The increasing risk of myocardial infarction from E2 through E4 was only observed in women. Compared with E3 homozygotes, the ORs associated with E2 and E4 were 0.52 (95\% CI: $0.17-1.62$ ) and 1.93 (95\% CI: 1.00-3.70), respectively, in women, while in men both ORs were equally elevated. As a result, the interaction between gender and APOE isoforms was statistically significant $(P=0.01)$. There were no statistically significant differences in the association 
TABLE 3: Odds ratios (ORs) and 95\% confidence intervals (CIs) for history of selected chronic diseases according to APOE genotypes.

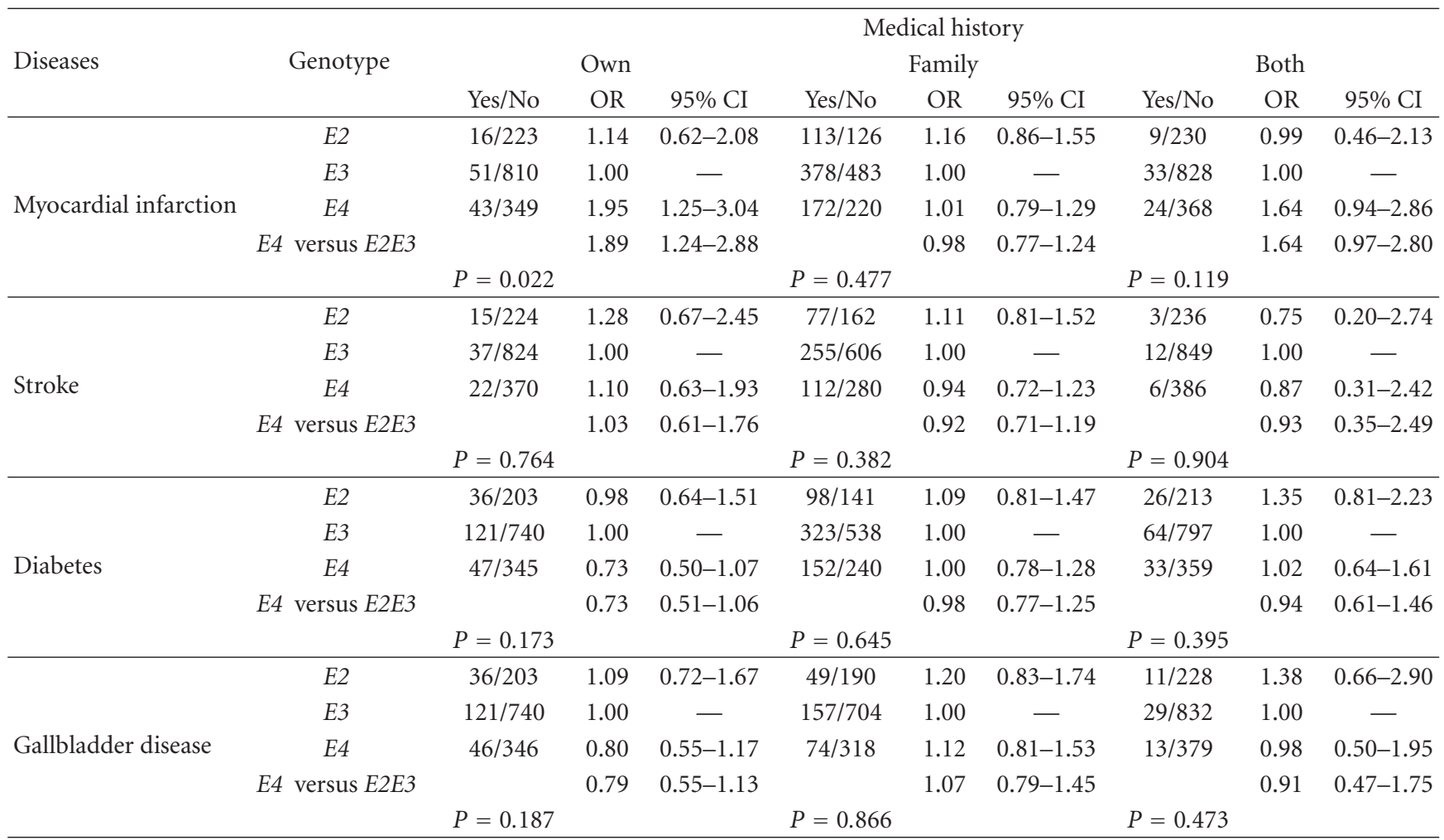

ORs were adjusted for age, sex, race, educational levels, cigarette smoking (pack-years), alcohol intake, body mass index, energy-adjusted dietary saturated fat, cholesterol, fiber and total calcium intakes, and family size, E2 includes E2/E2, E2/E3, and E2/E4, and E4 includes E4/E3, and E4/E4. $P$ values for a linear trend for E2, E3 and E4.

of $A P O E$ with diabetes by gender. The association of $A P O E$ isoforms with gallbladder disease was the opposite in men and women. In women the OR was the lowest with E4 (0.67, 95\% CI 0.43-1.06) and the highest with E2 (1.28, 95\% CI: $0.79-2.08)(P$ value for trend $=0.025)$, but in men it was the highest with E4 (1.14, 95\% CI: 0.58-2.26) and the lowest with E2 $(0.58,95 \%$ CI: $0.22-1.58)$ ( $P$ value for trend $=0.244)$. The interaction with gender was marginally statistically significant $(P=0.088)$. There were no significant interactions between $F A B P 2$ polymorphism and gender for any medical conditions (data not shown).

\section{Discussion}

The results of the present study are consistent with those in a few other studies that reported the significant effect of FABP2-T54 on the risk of myocardial infarction or coronary heart disease with the ORs ranging from 1.41 to 2.50 [3638]. It is interesting to note that the positive associations in these earlier studies were found in patients who were diagnosed with metabolic syndrome or had one of the conditions of the syndrome. Although we did not collect the information about hypertension, $59.5 \%$ of our study subjects had at least one condition that satisfied or was indicative of the criteria for metabolic syndrome, that is, obesity (BMI $\left.\left(\mathrm{kg} / \mathrm{m}^{2}\right) \geq 30\right)$, history of diabetes, or a history of high blood cholesterol (a surrogate marker for atherogenic dyslipidemia) [48]. Thus, these results suggest that other cardiovascular risk factors may be important effect modifiers of the FABP2 polymorphism and warrant further studies in populations with diverse risk profiles for CVD.

We also confirmed the association between $A P O E$ polymorphism and risk of myocardial infarction reported by many others [16-18], especially for E4 genotypes. Although the latest meta-analysis showed stepwise increases in total and LDL cholesterol levels and in risk of coronary heart disease from E2 homozygotes, E2 heterozygotes, E3/E3 wildtype, E4/E3, and E4 homozygotes [16], there were not enough subjects in each of the combinations, E2/E2 $(N=$ $11), E 2 / E 4(N=43)$, and $E 4 / E 4(N=42)$, to analyze them separately in our study. The exclusion of E2/E4 from the E2 group, however, had only nominal effects on the OR estimates associated with E2 genotypes. For example the OR for past history of MI changed from 1.14 (0.62-2.08) to 1.11 (0.58-2.13). Furthermore, our study and others suggest that the effects of $A P O E$ genotypes were greater in women than in men [19-25]. APOE is primarily produced in the liver, while it has been well documented that the liver is a sexually dimorphic organ. Hepatic gene expression is often sex specific, mediated through sex-dependent activation of several liver-enriched transcription factors in response to sex-specific secretion patterns of pituitary growth hormone $[49,50]$. In fact, higher circulating levels of APOE in 
TABLE 4: Odds ratios (ORs) and 95\% confidence intervals (CIs) for past history of selected chronic diseases according APOE genotypes and gender.

\begin{tabular}{|c|c|c|c|c|c|c|c|c|}
\hline \multirow{2}{*}{ Diseases } & \multirow{2}{*}{ Genotype } & \multicolumn{3}{|c|}{ Females } & \multicolumn{3}{|c|}{ Males } & \multirow{2}{*}{$P$ values for interaction } \\
\hline & & Yes/No & OR & $95 \% \mathrm{CI}$ & Yes/No & OR & $95 \% \mathrm{CI}$ & \\
\hline \multirow{5}{*}{ Myocardial infarction } & E2 & $4 / 129$ & 0.52 & $0.17-1.62$ & $12 / 94$ & 1.70 & $0.81-3.56$ & \\
\hline & E3 & $22 / 475$ & 1.00 & - & $29 / 335$ & 1.00 & - & \\
\hline & E4 & $21 / 205$ & 1.93 & $1.00-3.70$ & $22 / 144$ & 1.92 & $1.03-3.58$ & \\
\hline & $E 4$ versus $E 2 E 3$ & & 2.18 & $1.16-4.09$ & & 1.68 & $0.94-3.00$ & \\
\hline & & $P=0.009$ & & & $P=0.463$ & & & 0.008 \\
\hline \multirow{5}{*}{ Stroke } & E2 & $9 / 124$ & 1.34 & $0.57-3.15$ & $6 / 100$ & 1.22 & $0.42-3.55$ & \\
\hline & E3 & $21 / 476$ & 1.00 & - & $16 / 348$ & 1.00 & - & \\
\hline & E4 & $13 / 213$ & 1.11 & $0.53-2.33$ & $9 / 157$ & 1.05 & $0.42-2.61$ & \\
\hline & $E 4$ versus $E 2 E 3$ & & 1.03 & $0.51-2.06$ & & 1.00 & $0.42-2.38$ & \\
\hline & & $P=0.772$ & & & $P=0.846$ & & & 0.850 \\
\hline \multirow{5}{*}{ Diabetes } & E2 & $22 / 111$ & 0.99 & $0.56-1.73$ & $14 / 92$ & 0.93 & $0.47-1.87$ & \\
\hline & E3 & $68 / 429$ & 1.00 & - & $53 / 311$ & 1.00 & - & \\
\hline & E4 & $32 / 194$ & 0.89 & $0.55-1.44$ & $15 / 151$ & 0.50 & $0.26-0.97$ & \\
\hline & $E 4$ versus $E 2 E 3$ & & 0.89 & $0.56-1.42$ & & 0.51 & $0.27-0.97$ & \\
\hline & & $P=0.706$ & & & $P=0.103$ & & & 0.762 \\
\hline \multirow{5}{*}{ Gallbladder disease } & E2 & $31 / 102$ & 1.28 & $0.79-2.08$ & $5 / 101$ & 0.58 & $0.22-1.58$ & \\
\hline & E3 & $92 / 405$ & 1.00 & - & $29 / 335$ & 1.00 & - & \\
\hline & $E 4$ & $31 / 195$ & 0.67 & $0.43-1.06$ & $15 / 151$ & 1.14 & $0.58-2.26$ & \\
\hline & $E 4$ versus $E 2 E 3$ & & 0.64 & $0.41-0.99$ & & 1.27 & $0.66-2.46$ & \\
\hline & & $P=0.025$ & & & $P=0.244$ & & & 0.088 \\
\hline
\end{tabular}

ORs were adjusted for age, race, educational levels, cigarette smoking (pack-years), alcohol intake, body mass index, energy-adjusted dietary saturated fat, cholesterol, fiber and total calcium intakes, and family size. E2 includes E2/E2, E2/E3, and E2/E4, and E4 includes E4/E3 and E4/E4. P values for a linear trend for E2, E3 and E4.

females, female-predominant hepatic expression of fatty acid translocase and differential fatty acid compositions between males and females have been demonstrated in both humans and rodents [51-53]. Thus, effects of genetic polymorphisms may be more articulated in females through such transcriptional upregulation. This also explains the absence of the interaction between gender and FABP2 (intestinal type), whereas sex-dimorphic effects of FABP1 (liver-type) knockout have been noted in rodent models $[54,55]$.

Surprisingly few studies have addressed the association between the APOE polymorphism and risk of diabetes. However, our marginally significant inverse association with $E 4$ genotypes and past history of diabetes was consistent with a mouse model demonstrating that APOE deficiency abrogates insulin resistance [56] and with the observations in humans that the E4 genotypes were associated with a decreased risk and E2 genotypes with an increased risk of diabetes $[57,58]$. On the other hand, the associations between the FAPB2 polymorphism and diabetes remain inconsistent [59] despite the fact that the polymorphism has been associated with postprandial glucose and insulin levels $[26,34,35]$. Our study found the only modest association between T54 allele and family history, which was not confirmed with own history and thus likely to be a chance finding.

Excessive biliary cholesterol in conjunction with decreased bile acid output is the requisite for the formation of gallstones, particularly for cholesterol stones which account for the vast majority of this disease in Western countries and which are much more common in females than in males [60]. APOE plays a role not only in cholesterol metabolism but also in bile acid synthesis. Fecal bile acid output has been reported to be lowest in the subjects with $E 4$ allele, highest in the subjects with $E 2$ allele, and intermediate in the subjects with E3 homozygotes [61-65]. While the results of earlier studies are very mixed, some with a positive association with E4 [66-70], others with no association [71-74], and one with an inverse association $[75,76]$, the current study indicates that the effects of $A P O E$ may also be sex dependent, that is, a significantly reduced risk in women with $E 4$, but not in men. This corresponds to the APOE knockout mouse model where bile acid synthesis markedly varies by gender [77].

There are several limitations in this study. We realize that a certain degree of misclassification exists in self-reported past and family history of diseases, which is likely to bias the results toward a null association. As far as the medical conditions selected for this study are concerned, moderate to high agreement $(0.55-0.91$ as kappa statistics) has been observed between self-reports and in medical records [7880]. In addition, more than $50 \%$ of our study subjects had some college education [42], which further ensures the quality of self-reported data. Therefore, the magnitude of underestimation of the ORs is likely to be relatively small. Another concern is the coverage of disease spectra. Fatal cases of their own could not be included in this study, whereas fatal cases in their families may have been recalled more accurately. Thus, the interpretation of the ORs for 
past and family histories may differ particularly for CVD. Exclusion of fatal cases as well as cases who had severe complications especially in their speech may account for the small number of past histories of stroke reported in this study. Third, these chronic conditions stay asymptomatic for a long period of time. Thus, diagnoses of such asymptomatic cases depend on their preventive care or the presence of other conditions that require routine follow-up visits to health care professionals. Accordingly, some undiagnosed cases of diabetes and gallstones and subjects who underwent cardiac bypass or angioplasty without a heart attack were classified as a negative history in this study, which would further reduce potential differences between cases and noncases. Fourth, there is significant likelihood that some of the associations observed in this study were chance findings due to multiple comparisons in terms of outcome variables, although we focused on the two well-established functional polymorphisms. Finally, we acknowledge reverse temporal associations between the disease outcomes and some of the covariates included in the model, that is, smoking, BMI, and alcohol and dietary intake, which may have changed due to the diagnosis. However, these yielded predicted directions with histories of all diseases combined, that is, significant positive associations with cigarette smoking and BMI and inverse association with alcohol and calcium intake (data not shown). Although these adjustments may not have fully controlled confounding, it is less likely that the genotype distributions were affected by these covariates.

\section{Conclusions}

Despite the limitations discussed above, the results of the present study suggest that FBBP2-T54 allele is potential genetic marker for myocardial infarction and that the APOE4 isoform may exert opposite effects on myocardial infarction and gallstone disease in women, increasing risk for the former and decreasing risk for the later.

\section{Conflict of Interests}

The authors declare no Conflict of interests.

\section{Acknowledgment}

This work was supported by a Research Grant from the US National Institutes of Health R01-CA93817.

\section{References}

[1] D. B. Jump, D. Botolin, Y. Wang, J. Xu, and B. Christian, "Fatty acids and gene transcription," Scandinavian Journal of Food and Nutrition, vol. 50, no. 2, pp. 5-12, 2006.

[2] C. J. Willer, S. Sanna, A. U. Jackson et al., "Newly identified loci that influence lipid concentrations and risk of coronary artery disease," Nature Genetics, vol. 40, no. 2, pp. 161-169, 2008.

[3] M. Beekman, B. T. Heijmans, N. G. Martin et al., "Heritabilities of apolipoprotein and lipid levels in three countries," Twin Research, vol. 5, no. 2, pp. 87-97, 2002.
[4] D. I. Boomsma, H. J. M. Kempen, J. A. Gevers Leuven, L. Havekes, P. De Knijff, and R. R. Frants, "Genetic analysis of sex and generation differences in plasma lipid, lipoprotein, and apolipoprotein levels in adolescent twins and their parents," Genetic Epidemiology, vol. 13, no. 1, pp. 49-60, 1996.

[5] D. A. Heller, U. de Faire, N. L. Pedersen, G. Dahlén, and G. E. McClearn, "Genetic and environmental influences on serum lipid levels in twins," The New England Journal of Medicine, vol. 328, no. 16, pp. 1150-1156, 1993.

[6] A. Iliadou, P. Lichtenstein, U. de Faire, and N. L. Pedersen, "Variation in genetic and environmental influences in serum lipid and apolipoprotein levels across the lifespan in Swedish male and female twins," American Journal of Medical Genetics, vol. 102, no. 1, pp. 48-58, 2001.

[7] G. V. Z. Dedoussis, "Apolipoprotein polymorphisms and familial hypercholesterolemia," Pharmacogenomics, vol. 8, no. 9, pp. 1179-1189, 2007.

[8] A. M. Minihane, "Fatty acid-genotype interactions and cardiovascular risk," Prostaglandins Leukotrienes and Essential Fatty Acids, vol. 82, no. 4-6, pp. 259-264, 2010.

[9] P. Perez-Martinez, J. Lopez-Miranda, F. Perez-Jimenez, and J. M. Ordovas, "Influence of genetic factors in the modulation of postprandial lipemia," Atherosclerosis Supplements, vol. 9, no. 2, pp. 49-55, 2008.

[10] S. Kathiresan, O. Melander, C. Guiducci et al., "Six new loci associated with blood low-density lipoprotein cholesterol, high-density lipoprotein cholesterol or triglycerides in humans," Nature Genetics, vol. 40, no. 2, pp. 189-197, 2008.

[11] S. Kathiresan, C. J. Willer, G. M. Peloso et al., "Common variants at 30 loci contribute to polygenic dyslipidemia," Nature Genetics, vol. 41, no. 1, pp. 56-65, 2009.

[12] J. E. Eichner, S. T. Dunn, G. Perveen, D. M. Thompson, K. E. Stewart, and B. C. Stroehla, "Apolipoprotein E polymorphism and cardiovascular disease: a HuGE review," American Journal of Epidemiology, vol. 155, no. 6, pp. 487-495, 2002.

[13] K. Greenow, N. J. Pearce, and D. P. Ramji, "The key role of apolipoprotein e in atherosclerosis," Journal of Molecular Medicine, vol. 83, no. 5, pp. 329-342, 2005.

[14] D. M. Hatters, C. A. Peters-Libeu, and K. H. Weisgraber, "Apolipoprotein E structure: insights into function," Trends in Biochemical Sciences, vol. 31, no. 8, pp. 445-454, 2006.

[15] A. M. Minihane, L. Jofre-Monseny, E. Olano-Martin, and G. Rimbach, "ApoE genotype, cardiovascular risk and responsiveness to dietary fat manipulation," Proceedings of the Nutrition Society, vol. 66, no. 2, pp. 183-197, 2007.

[16] A. M. Bennet, E. Di Angelantonio, Z. Ye et al., "Association of apolipoprotein E genotypes with lipid levels and coronary risk," Journal of the American Medical Association, vol. 298, no. 11, pp. 1300-1311, 2007.

[17] P. W. Wilson, E. J. Schaefer, M. G. Larson, and J. M. Ordovas, "Apolipoprotein E alleles and risk of coronary disease. A metaanalysis," Arteriosclerosis, Thrombosis, and Vascular Biology, vol. 16, no. 10, pp. 1250-1255, 1996.

[18] Y. Song, M. J. Stampfer, and S. Liu, "Meta-analysis: apolipoprotein E genotypes and risk for coronary heart disease," Annals of Internal Medicine, vol. 141, no. 2, pp. 137-147, 2004.

[19] G. D. Kolovou, D. Damaskos, K. Anagnostopoulou, and D. V. Cokkinos, "Apolipoprotein E gene polymorphism and gender," Annals of Clinical and Laboratory Science, vol. 39, no. 2, pp. 120-133, 2009. 
[20] D. Gómez-Coronado, J. J. Alvarez, A. Entrala, J. M. Olmos, E. Herrera, and M. A. Lasunción, "Apolipoprotein E polymorphism in men and women from a Spanish population: allele frequencies and influence on plasma lipids and apolipoproteins," Atherosclerosis, vol. 147, no. 1, pp. 167-176, 1999.

[21] K. E. Zerba, R. E. Ferrell, and C. F. Sing, "Genotypeenvironment interaction: apolipoprotein $\mathrm{E}$ (ApoE) gene effects and age as an index of time and spatial context in the human," Genetics, vol. 143, no. 1, pp. 463-478, 1996.

[22] R. Elosua, J. M. Ordovas, L. A. Cupples et al., "Association of APOE genotype with carotid atherosclerosis in men and women: the Framingham Heart Study," Journal of Lipid Research, vol. 45, no. 10, pp. 1868-1875, 2004.

[23] R. Frikke-Schmidt, B. G. Nordestgaard, B. Agerholm-Larsen, P. Schnohr, and A. Tybjaerg-Hansen, "Context-dependent and invariant associations between lipids, lipoproteins, and apolipoproteins and apolipoprotein E genotype," Journal of Lipid Research, vol. 41, no. 11, pp. 1812-1822, 2000.

[24] C. Lahoz, E. J. Schaefer, L. A. Cupples et al., "Apolipoprotein E genotype and cardiovascular disease in the Framingham Heart Study," Atherosclerosis, vol. 154, no. 3, pp. 529-537, 2001.

[25] R. W. Mahley, J. Pépin, K. E. Palaoğlu, M. J. Malloy, J. P. Kane, and T. P. Bersot, "Low levels of high density lipoproteins in Turks, a population with elevated hepatic lipase. High density lipoprotein characterization and gender-specific effects of apolipoprotein E genotype," Journal of Lipid Research, vol. 41, no. 8, pp. 1290-1301, 2000.

[26] L. J. Baier, J. C. Sacchettini, W. C. Knowler et al., "An amino acid substitution in the human intestinal fatty acid binding protein is associated with increased fatty acid binding, increased fat oxidation and insulin resistance," Journal of Clinical Investigation, vol. 95, no. 3, pp. 1281-1287, 1995.

[27] L. J. Baier, C. Bogardus, and J. C. Sacchettini, "A polymorphism in the human intestinal fatty acid binding protein alters fatty acid transport across Caco-2 cells," Journal of Biological Chemistry, vol. 271, no. 18, pp. 10892-10896, 1996.

[28] A. Georgopoulos, O. Aras, and M. Y. Tsai, "Codon-54 polymorphism of the fatty acid-binding protein 2 gene is associated with elevation of fasting and postprandial triglyceride in type 2 diabetes," Journal of Clinical Endocrinology and Metabolism, vol. 85, no. 9, pp. 3155-3160, 2000.

[29] R. A. Hegele, P. W. Connelly, A. J. G. Hanley, F. Sun, S. B. Harris, and B. Zinman, "Common genomic variants associated with variation in plasma lipoproteins in young aboriginal Canadians," Arteriosclerosis, Thrombosis, and Vascular Biology, vol. 17, no. 6, pp. 1060-1066, 1997.

[30] J. Pihlajamäki, J. Rissanen, S. Heikkinen, L. Karjalainen, and M. Laakso, "A codon 54 polymorphism of the human intestinal fatty acid binding protein 2 gene is associated with dyslipidemias but not with insulin resistance in patients with familial combined hyperlipidemia," Arteriosclerosis, Thrombosis, and Vascular Biology, vol. 17, no. 6, pp. 1039-1044, 1997.

[31] H. M. Vidgren, R. H. Sipiläinen, S. Heikkinen, M. Laakso, and M. I. J. Uusitupa, "Threonine allele in codon 54 of the fatty acid binding protein 2 gene does not modify the fatty acid composition of serum lipids in obese subjects," European Journal of Clinical Investigation, vol. 27, no. 5, pp. 405-408, 1997.

[32] J. J. Ågren, R. Valve, H. Vidgren, M. Laakso, and M. Uusitupa, "Postprandial lipemic response is modified by the polymorphism at codon 54 of the fatty acid-binding protein 2 gene," Arteriosclerosis, Thrombosis, and Vascular Biology, vol. 18, no. 10, pp. 1606-1610, 1998.
[33] J. J. Ågren, H. M. Vidgren, R. S. Valve, M. Laakso, and M. I. Uusitupa, "Postprandial responses of individual fatty acids in subjects homozygous for the threonine- or alanine-encoding allele in codon 54 of the intestinal fatty acid binding protein 2 gene," American Journal of Clinical Nutrition, vol. 73, no. 1, pp. 31-35, 2001.

[34] K. Yamada, X. Yuan, S. Ishiyama et al., "Association between Ala54Thr substitution of the fatty acid-binding protein 2 gene with insulin resistance and intra-abdominal fat thickness in Japanese men," Diabetologia, vol. 40, no. 6, pp. 706-710, 1997.

[35] R. A. Hegele, T. K. Young, and P. W. Connelly, "Are Canadian Inuit at increased genetic risk for coronary heart disease?" Journal of Molecular Medicine, vol. 75, no. 5, pp. 364-370, 1997.

[36] A. Georgopoulos, H. Bloomfield, D. Collins et al., "Codon 54 polymorphism of the fatty acid binding protein (FABP) 2 gene is associated with increased cardiovascular risk in the dyslipidemic diabetic participants of the Veterans Affairs HDL intervention trial (VA-HIT)," Atherosclerosis, vol. 194, no. 1, pp. 169-174, 2007.

[37] K. Nishihama, Y. Yamada, H. Matsuo et al., "Association of gene polymorphisms with myocardial infarction in individuals with or without conventional coronary risk factors," International Journal of Molecular Medicine, vol. 19, no. 1, pp. 129-141, 2007.

[38] M. Oguri, K. Kato, K. Yokoi et al., "Association of genetic variants with myocardial infarction in Japanese individuals with metabolic syndrome," Atherosclerosis, vol. 206, no. 2, pp. 486-493, 2009.

[39] P. Wanby, P. Palmquist, I. Rydén, L. Brattström, and M. Carlsson, "The FABP2 gene polymorphism in cerebrovascular disease," Acta Neurologica Scandinavica, vol. 110, no. 6, pp. 355-360, 2004.

[40] Y. Yamada, K. Kato, M. Oguri et al., "Association of genetic variants with atherothrombotic cerebral infarction in Japanese individuals with metabolic syndrome," International Journal of Molecular Medicine, vol. 21, no. 6, pp. 801-808, 2008.

[41] C. Albala, A. Villarroel, J. L. Santos et al., "FABP2 Ala54Thr polymorphism and diabetes in Chilean elders," Diabetes Research and Clinical Practice, vol. 77, no. 2, pp. 245-250, 2007.

[42] I. Kato, S. Land, A. P. Majumdar, J. Barnholtz-Sloan, and R. K. Severson, "Functional polymorphisms to modulate luminal lipid exposure and risk of colorectal cancer," Cancer Epidemiology, vol. 34, no. 3, pp. 291-297, 2010.

[43] G. Block, M. Woods, A. Potosky, and C. Clifford, "Validation of a self-administered diet history questionnaire using multiple diet records," Journal of Clinical Epidemiology, vol. 43, no. 12, pp. 1327-1335, 1990.

[44] G. Block, F. E. Thompson, A. M. Hartman, F. A. Larkin, and K. E. Guire, "Comparison of two dietary questionnaires validated against multiple dietary records collected during a 1year period," Journal of the American Dietetic Association, vol. 92, no. 6, pp. 686-693, 1992.

[45] A. K. Wirfält, R. W. Jeffery, and P. J. Elmer, "Comparison of food frequency questionnaires: the reduced Block and Willett questionnaires differ in ranking on nutrient intakes," American Journal of Epidemiology, vol. 148, no. 12, pp. 1148-1156, 1998.

[46] W. Willett and M. J. Stampfer, "Total energy intake: implications for epidemiologic analyses," American Journal of Epidemiology, vol. 124, no. 1, pp. 17-27, 1986.

[47] N. E. Breslow and N. E. Day, "Statistical methods in cancer research, vol 1, the analysis of case-control studies," International Aerial Robotics Competition Scientific Publications, no. 32, pp. 5-338, 1980. 
[48] S. M. Grundy, J. I. Cleeman, S. R. Daniels et al., "Diagnosis and management of the metabolic syndrome: an American Heart Association/National Heart, Lung, and Blood Institute Scientific Statement," Circulation, vol. 112, no. 17, pp. 27352752, 2005.

[49] C. A. Wiwi and D. J. Waxman, "Role of hepatocyte nuclear factors in growth hormone-regulated, sexually dimorphic expression of liver cytochromes P450," Growth Factors, vol. 22, no. 2, pp. 79-88, 2004.

[50] D. J. Waxman and C. O'Connor, “Growth hormone regulation of sex-dependent liver gene expression," Molecular Endocrinology, vol. 20, no. 11, pp. 2613-2629, 2006.

[51] J. Oscarsson, S. O. Olofsson, K. Vikman, and S. Edén, "Growth hormone regulation of serum lipoproteins in the rat: different growth hormone regulatory principles for apolipoprotein (apo) B and the sexually dimorphic apo E concentrations," Metabolism, vol. 40, no. 11, pp. 1191-1198, 1991.

[52] N. Ståhlberg, E. Rico-Bautista, R. M. Fisher et al., "Femalepredominant expression of fatty acid translocase/CD36 in rat and human liver," Endocrinology, vol. 145, no. 4, pp. 19721979, 2004.

[53] J. Oscarsson and S. Edén, "Sex differences in fatty acid composition of rat liver phosphatidylcholine are regulated by the plasma pattern of growth hormone," Biochimica et Biophysica Acta, vol. 959, no. 3, pp. 280-287, 1988.

[54] G. G. Martin, B. P. Atshaves, A. L. McIntosh, J. T. Mackie, A. B. Kier, and F. Schroeder, "Liver fatty acid binding protein gene ablation potentiates hepatic cholesterol accumulation in cholesterol-fed female mice," American Journal of PhysiologyGastrointestinal and Liver Physiology, vol. 290, no. 1, pp. G36G48, 2006.

[55] Y. Xie, E. P. Newberry, S. M. Kennedy, J. Luo, and N. O. Davidson, "Increased susceptibility to diet-induced gallstones in liver fatty acid binding protein knockout mice," Journal of Lipid Research, vol. 50, no. 5, pp. 977-987, 2009.

[56] Y. Kawashima, J. Chen, H. Sun et al., "Apolipoprotein E deficiency abrogates insulin resistance in a mouse model of type 2 diabetes mellitus," Diabetologia, vol. 52, no. 7, pp. 14341441, 2009.

[57] L. A. Profenno and S. V. Faraone, "Diabetes and overweight associate with non-APOE4 genotype in an Alzheimer's disease population," American Journal of Medical Genetics_Part B, vol. 147B, no. 6, pp. 822-829, 2008.

[58] F. I. Errera, M. E. Silva, E. Yeh et al., "Effect of polymorphisms of the MTHFR and APOE genes on susceptibility to diabetes and severity of diabetic retinopathy in Brazilian patients," Brazilian Journal of Medical and Biological Research, vol. 39, no. 7, pp. 883-888, 2006.

[59] A. Tavridou, K. I. Arvanitidis, A. Tiptiri-Kourpeti et al., "Thr54 allele of fatty-acid binding protein 2 gene is associated with obesity but not type 2 diabetes mellitus in a Caucasian population," Diabetes Research and Clinical Practice, vol. 84, no. 2, pp. 132-137, 2009.

[60] D. E. Johnston and M. M. Kaplan, "Pathogenesis and treatment of gallstones," The New England Journal of Medicine, vol. 328, no. 6, pp. 412-421, 1993.

[61] Y. A. Kesäniemi, C. Ehnholm, and T. A. Miettinen, "Intestinal cholesterol absorption efficiency in man is related to apoprotein E phenotype," Journal of Clinical Investigation, vol. 80, no. 2, pp. 578-581, 1987.
[62] T. A. Miettinen, H. Gylling, H. Vanhanen, and A. Ollus, "Cholesterol absorption, elimination, and synthesis related to LDL kinetics during varying fat intake in men with different apoprotein E phenotypes," Arteriosclerosis and Thrombosis, vol. 12, no. 9, pp. 1044-1052, 1992.

[63] H. Gylling, K. Aalto-Setälä, K. Kontula, and T. A. Miettinen, "Serum low density lipoprotein cholesterol level and cholesterol absorption efficiency are influenced by apolipoprotein $\mathrm{B}$ and $\mathrm{E}$ polymorphism and by the $\mathrm{FH}-$ Helsinki mutation of the low density lipoprotein receptor gene in familial hypercholesterolemia," Arteriosclerosis and Thrombosis, vol. 11, no. 5, pp. 1368-1375, 1991.

[64] H. Gylling, K. Kontula, and T. A. Miettinen, "Cholesterol absorption and metabolism and LDL kinetics in healthy men with different apoprotein $\mathrm{E}$ phenotypes and apoprotein B Xba I and LDL receptor Pvu II genotypes," Arteriosclerosis, Thrombosis, and Vascular Biology, vol. 15, no. 2, pp. 208-213, 1995.

[65] H. Gylling, K. Kontula, U. M. Koivisto, H. E. Miettinen, and T. A. Miettinen, "Polymorpohisms of the genes encoding apoproteins A-I, B, C-III, and E and LDL receptor, and cholesterol and LDL metabolism during increased cholesterol intake," Arteriosclerosis, Thrombosis, and Vascular Biology, vol. 17, no. 1, pp. 38-44, 1997.

[66] M. Niemi, K. Kervinen, A. Rantala et al., "The role of apolipoprotein $\mathrm{E}$ and glucose intolerance in gallstone disease in middle aged subjects," Gut, vol. 44, no. 4, pp. 557-562, 1999.

[67] A. Bertomeu, E. Ros, D. Zambón et al., "Apolipoprotein E polymorphism and gallstones," Gastroenterology, vol. 111, no. 6, pp. 1603-1610, 1996.

[68] S. Fischer, M. H. Dolu, B. Zündt, G. Meyer, S. Geisler, and D. Jüngst, "Apolipoprotein E polymorphism and lithogenic factors in gallbladder bile," European Journal of Clinical Investigation, vol. 31, no. 9, pp. 789-795, 2001.

[69] K. J. van Erpecum, P. Portincasa, M. H. Dohlu, G. P. van Berge-Henegouwen, and D. Jüngst, "Biliary pronucleating proteins and apolipoprotein $\mathrm{E}$ in cholesterol and pigmentstone patients," Journal of Hepatology, vol. 39, no. 1, pp. 7-11, 2003.

[70] P. Portincasa, K. J. van Erpecum, P. C. van De Meeberg, G. M. Dallinga-Thie, T. W. A. De Bruin, and G. P. Van BergeHenegouwen, "Apolipoprotein E4 genotype and gallbladder motility influence speed of gallstone clearance and risk of recurrence after extracorporeal shock-wave lithotripsy," Hepatology, vol. 24, no. 3, pp. 580-587, 1996.

[71] M. Dixit, G. Choudhuri, and B. Mittal, "Association of APOE-C1 gene cluster polymorphisms with gallstone disease," Digestive and Liver Disease, vol. 38, no. 6, pp. 397-403, 2006.

[72] Z. Y. Jiang, T. Q. Han, G. J. Suo et al., "Polymorphisms at cholesterol $7 \alpha$-hydroxylase, apolipoproteins B and E and low density lipoprotein receptor genes in patients with gallbladder stone disease," World Journal of Gastroenterology, vol. 10, no. 10, pp. 1508-1512, 2004.

[73] K. Hasegawa, S. Terada, K. Kubota et al., "Effect of apolipoprotein $\mathrm{E}$ polymorphism on bile lipid composition and the formation of cholesterol gallstone," American Journal of Gastroenterology, vol. 98, no. 7, pp. 1605-1609, 2003.

[74] C. W. Ko. Cynthia, S. A. A. Beresford, B. Alderman et al., "Apolipoprotein E genotype and the risk of gallbladder disease in pregnancy," Hepatology, vol. 31, no. 1, pp. 18-23, 2000.

[75] Q. Y. Lin, J. P. Du, M. Y. Zhang et al., "Effect of apolipoprotein E gene Hha I restricting fragment length polymorphism on serum lipids in cholecystolithiasis," World Journal of Gastroenterology, vol. 5, no. 3, pp. 228-230, 1999. 
[76] L. L. Boland, A. R. Folsom, E. Boerwinkle et al., "Atherosclerosis Risk in Communities (ARIC) Study Investigators. Apolipoprotein E genotype and gallbladder disease risk in a large population-based cohort," Annals of Epidemiology, vol. 16, no. 10 , pp. 763-769, 2006.

[77] H. B. Hartman, S. J. Gardell, C. J. Petucci, S. Wang, J. A. Krueger, and M. J. Evans, "Activation of farnesoid X receptor prevents atherosclerotic lesion formation in LDLR-/- and apoE-/- mice," Journal of Lipid Research, vol. 50, no. 6, pp. 1090-1100, 2009.

[78] C. Bosetti, A. Tavani, E. Negri, D. Trichopoulos, and C. La Vecchia, "Reliability of data on medical conditions, menstrual and reproductive history provided by hospital controls," Journal of Clinical Epidemiology, vol. 54, no. 9, pp. 902-906, 2001.

[79] O. H. Klungel, A. de Boer, A. H. P. Paes, J. C. Seidell, and A. Bakker, "Cardiovascular diseases and risk factors in a population-based study in The Netherlands: agreement between questionnaire information and medical records," Netherlands Journal of Medicine, vol. 55, no. 4, pp. 177-183, 1999.

[80] F. Kee, L. Tiret, J. Y. Robo et al., "Reliability of reported family history of myocardial infarction," British Medical Journal, vol. 307, no. 6918, pp. 1528-1530, 1993. 


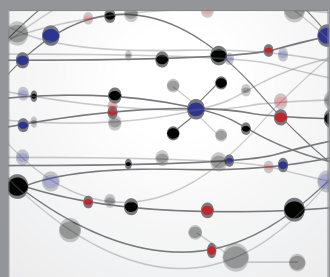

The Scientific World Journal
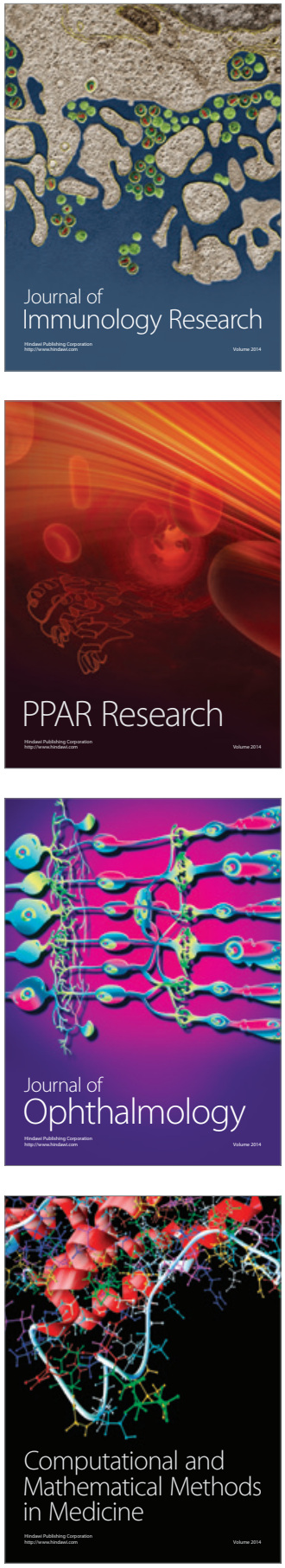

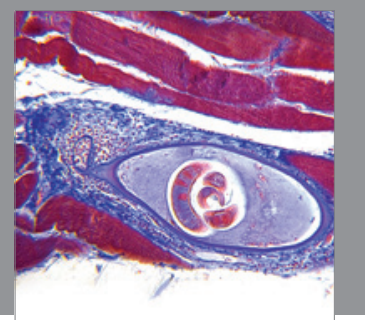

Gastroenterology

Research and Practice
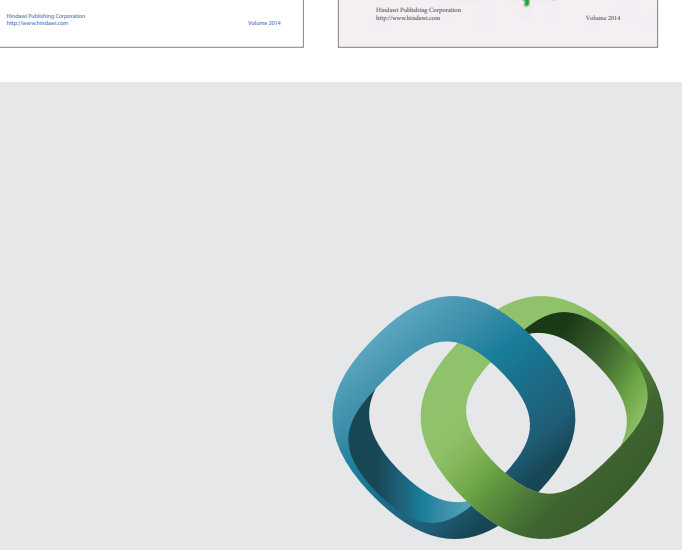

\section{Hindawi}

Submit your manuscripts at

http://www.hindawi.com
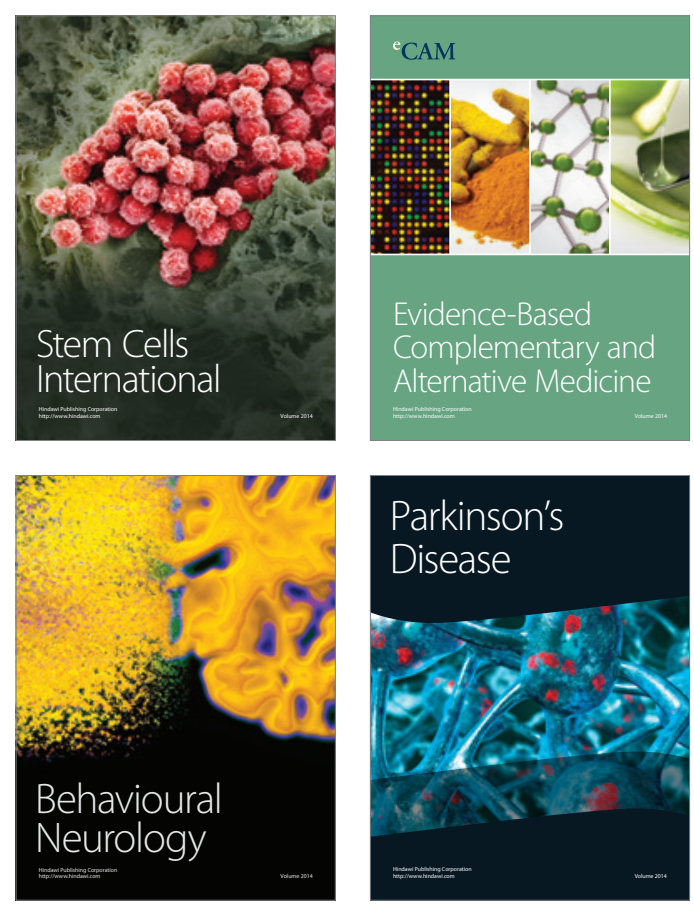

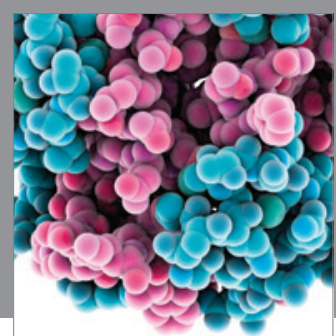

Journal of
Diabetes Research

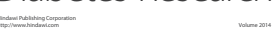

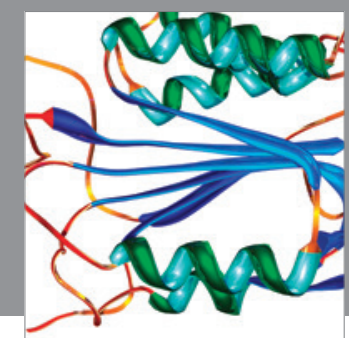

Disease Markers
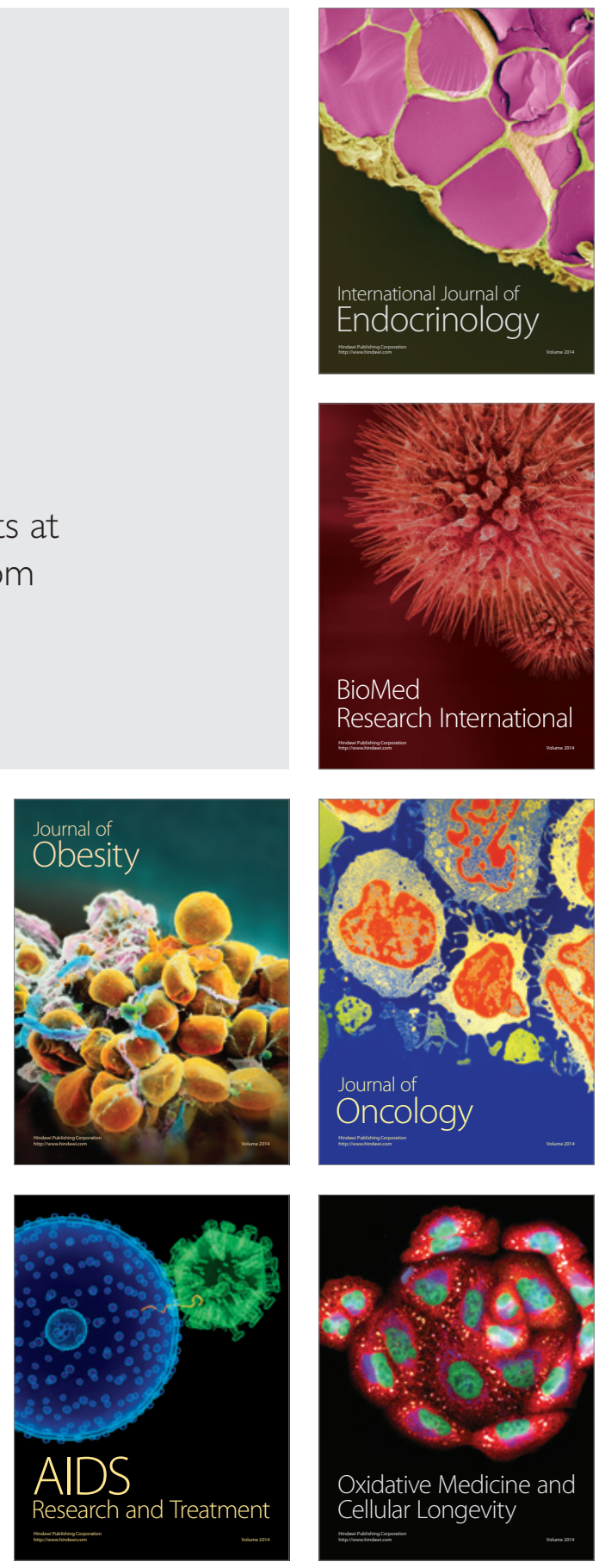